\title{
Uso de técnicas de geoprocessamento na otimização do traçado de sistemas adutores de abastecimento de água com a utilização de uma base de dados de alta definição
}

\author{
Use of geoprocessing techniques in the optimization of the pipeline \\ alignment of water supply systems with the use of a high definition database
}

Francisco Eudes do Amaral"* ${ }^{10}$, José Almir Cirilo² $(\mathbb{1}$, Alfredo Ribeiro Neto'

口

\section{RESUMO}

Neste trabalho discute-se um modelo de otimização multicritério baseado em Sistemas de Informações Geográficas (SIGs), que tem por finalidade a determinação dos locais com maior potencial para locação do traçado de adutoras por meio da utilização de variáveis de custo, bem como do melhor caminho para esse traçado. Em decorrência disso, foi possível simular rotas de custo mínimo para o traçado da adutora, considerando critérios relacionados com: as declividades e as altitudes da área, as distâncias de rios e áreas alagadas e a proximidade de rodovias. A análise leva em consideração a importância (peso) de cada critério no modelo. Para minimizar a subjetividade na escolha dos valores desses pesos, buscou-se a opinião de especialistas com relação aos critérios analisados. O método Análise Hierárquica de Pesos (AHP) foi utilizado para a ponderação dos critérios. Para aplicação da metodologia, utilizou-se como área de estudo um trecho da Adutora do Pajeú no Estado de Pernambuco e uma base de dados de alta definição do Programa Pernambuco Tridimensional (Programa PE3D), além da base de dados Shuttle Radar Topography Mission (SRTM)/TOPODATA. Os resultados obtidos por meio de SIG permitiram identificar as áreas consideradas de maior aptidão para a locação do traçado da adutora e determinar uma rota otimizada para esse traçado. Na prática, significou na determinação de uma rota para implantação da tubulação da adutora, o que sugere que a utilização de SIG e técnicas de otimização pode auxiliar a tomada de decisão no que se refere aos projetos de sistemas adutores de abastecimento de água.

Palavras-chave: adutoras; otimização de rotas; sistemas de informações geográficas

\begin{abstract}
This paper discusses a multi-criteria GIS-based optimization model, which aims to determine the locations with the highest potential for the location of the water mains through the use of cost variables, as well as the best path for this tracing. As a result, it was possible to simulate minimum cost routes for the pipeline layout, considering criteria related to: the slope and altitude of the area, the distances of rivers and flooded areas and the proximity of highways. The analysis takes into account the importance (weight) of each criterion in the model. To minimize subjectivity in choosing the values of these weights, expert opinion was sought regarding the criteria analyzed. The HWA (Hierarchical Weight Analysis) method was used to weigh the criteria. To apply the methodology, the study area used an excerpt from the Pajeú pipeline in the state of Pernambuco and a high definition database from the Pernambuco Three-dimensional Program, as well as the SRTM/ TOPODATA database. The results obtained through GIS allowed us to identify the areas considered to be the most suitable for the location of the pipeline and to determine an optimized route for this route. In practice, it meant determining a route for the pipeline installation, which suggests that the use of GIS and optimization techniques can help decision making regarding the design of water supply systems.
\end{abstract}

Keywords: pipeline; route optimization; geographic information systems.

'Centro de Tecnologia e Geociências, Universidade Federal de Pernambuco - Recife (PE), Brasil.

${ }^{2}$ Centro Acadêmico do Agreste, Universidade Federal de Pernambuco - Caruaru (PE), Brasil.

*Autor correspondente: eudesuned@hotmail.com

Recebido: 02/04/2018 - Aceito: 11/03/2019 - Reg. Abes: 193734 


\section{INTRODUÇÃO}

Muitos municípios brasileiros, como os localizados na região da bacia hidrográfica do rio Pajeú, Estado de Pernambuco, estão enfrentando aumentos populacionais, e uma consequência disso é uma pressão maior sobre os recursos hídricos dessas cidades. Uma das preocupações mais prementes é a disponibilidade de água potável, já que muitas dessas cidades dependem fortemente de reservas de água que estão se esgotando de forma acelerada.

As estratégias para atender essa crescente demanda urbana por água passam pelos sistemas de abastecimento. $\mathrm{O}$ dimensionamento, a implantação do projeto, a operação e a manutenção de um sistema de abastecimento de água envolvem custos bastante elevados, impactos ambientais, sociais e econômicos, e merecem análises hidrológica, hidráulica e operacional consistente (LACERDA, 2009). Isso significa que as unidades que compõem esses sistemas devem ser cuidadosamente dimensionadas de maneira que os custos delas sejam otimizados. Entre as unidades de um sistema de abastecimento de água, dependendo do seu porte, a adução é uma das que representam maior custo de implantação. As principais variáveis que mais influenciam no custo de uma adutora são: a tubulação, que depende do diâmetro e do seu material; a escavação para sua implantação, que depende principalmente do tipo de solo; e a extensão dos tubos que depende fundamentalmente do traçado adotado para a adutora.

Os Sistemas de Informações Geográficas (SIGs) consistem em ferramentas capazes de tratar a informação em todo o seu ciclo de vida. Segundo Elmasri e Navathe (2004), esses sistemas são utilizados para coletar, modelar, armazenar e analisar informações que descrevem propriedades físicas do mundo geográfico, permitindo assim gerenciar e tratar informações geográficas. Nesse sentido, os SIGs são ferramentas que podem ser utilizadas como instrumento de apoio à tomada de decisão quanto ao traçado de adutoras, pois muitos dos critérios utilizados estão relacionados com variáveis espaciais. As ferramentas de geoprocessamento são aplicadas de diferentes formas nesse tipo de estudo. Há exemplos em que o traçado é definido de forma heurística, em que se testam diversos arranjos até que se encontre aquele que apresenta o menor custo (ROY et al., 2017; LUETTINGER; CLARK, 2005), outros que utilizam ferramentas de otimização de rede (SALAH; ATWOOD, 2011; YLDIRIM; YOMRALIOGLU, 2011; NONIS; VARGHESE; SURESH, 2007), em que se utilizam critérios como custos e características físicas para maximizar ou minimizar uma função-objetivo. O uso de ferramentas SIG não se limita a aplicações para traçado de adutoras para transporte de água. Dutos para transporte de petróleo também são exemplos de projetos que utilizam SIG para a definição de traçado (HUSEYNLI, 2015; BALOGUN et al., 2012). Huseynli (2015) mostra a viabilidade do uso dessa ferramenta cujos objetivos foram reduzir impactos sobre o meio ambiente e a agricultura e prevenir contra perigos naturais. $\mathrm{O}$ autor utilizou camadas raster, como declividade do terreno, geologia, uso da terra e população, no software ArcGIS para encontrar a rota de menor custo. Alguns desses trabalhos utilizaram a ferramenta Spatial Analyst (BALOGUN et al., 2012; HUSEYNLI, 2015; SALAH; ATWOOD, 2011) junto à atribuição de pesos para as camadas raster utilizadas na análise.

Outro aspecto explorado neste trabalho diz respeito ao uso do Modelo Digital do Terreno (MDT) de alta resolução como base para a definição de traçados. Roy et al. (2017) chamam a atenção para as vantagens do uso de produtos de sensoriamento remoto de alta resolução para aplicação em projetos de rede de distribuição de água de média escala em plataformas geoespaciais. Nesse ponto, a aplicação apresentada no presente trabalho destaca-se em virtude de a resolução do MDT utilizado ser sensivelmente superior a outras aplicações que usaram resolução de 30 m (ROY et al., 2017) e 90 m (HUSEYNLI, 2015).

$\mathrm{O}$ presente trabalho caracteriza-se por utilizar as ferramentas de SIG consagradas na literatura para o traçado de adutoras e dutos de petróleo e gás, aliado ao uso de dado da elevação do terreno com alta resolução e precisão. A hipótese é que tal combinação acarreta ganho significativo para o estudo das técnicas e das ferramentas utilizadas na definição dos traçados.

Considerando as alternativas de processo de seleção de rotas, discute-se, neste trabalho, um modelo de otimização baseado em SIG que tem por finalidade a determinação dos locais de maior aptidão para a locação do traçado de adutoras, por meio da utilização de imagens matriciais de custo (planos de informação), bem como do melhor caminho para esse traçado. Em decorrência disso, é possível simular rotas de custo mínimo para o traçado de adutoras, considerando critérios exclusivamente técnicos, relacionados com as declividades e as altitudes da área, as distâncias de rios/áreas alagadas e a proximidade de rodovias.

A maioria das ferramentas atuais utiliza processos manuais e não permite a integração direta e automática com outros pacotes de software. A geração manual de rotas envolve a intervenção direta do projetista, tornando o processo relativamente demorado. Nesse sentido, o uso de SIG e de ferramentas e aplicações que permitam a automação desse processo provoca uma diminuição de custos de construção e manutenção e reduz consideravelmente o tempo na tomada de decisão. Pensando na importância dos sistemas adutores no que se refere ao abastecimento de água para as regiões onde estão localizados, é de suma importância que sejam propostas soluções que visam à otimização desse tipo de projeto, por meio da locação de traçados (rotas) de custo mínimo.

O objetivo deste trabalho foi desenvolver um modelo de otimização baseado em SIG que realiza uma análise espacial para determinação do melhor caminho (menor custo) na implantação de uma rota (traçado) em sistemas adutores. Especificamente, objetivam-se:

- a seleção de áreas consideradas de maior aptidão para a locação do traçado de adutoras com base nos custos associados à sua construção e manutenção; 
- a determinação de uma rota (traçado) otimizada para implantação da tubulação da adutora.

- aplicar o modelo desenvolvido no projeto do Sistema Adutor do Pajeú e identificar uma rota (traçado) de menor custo.

\section{METODOLOGIA}

\section{Determinação de rotas baseadas em Sistemas de Informações Geográficas}

Como apontam Hardin, Bridges e Rundeli (2008), a seleção de rotas para o traçado de adutoras não pode ser desenvolvida apenas com base na opinião subjetiva dos projetistas, em que são considerados somente os conhecimentos desses profissionais acerca das condições atuais e das restrições em determinada área. Faz-se necessária a utilização dos avanços atuais das tecnologias de SIG, que estão permitindo que profissionais de engenharia possam determinar o caminho de menor custo entre os pontos de origem e destino do traçado de uma adutora. Adicionalmente, a localização ou a disposição espacial mais adequada de componentes de sistemas de abastecimento de água, como adutoras e redes de distribuição, é de grande relevância, considerando a importância da qualidade de serviços a serem prestados à sociedade. Estudos têm sido desenvolvidos com esse objetivo, como é o caso do trabalho de pesquisa efetuado por Cordão, Rufino e Araújo (2013), que apresenta uma alternativa para indicar áreas ótimas para a localização de unidades de reservação, e fundamenta-se na utilização de técnicas que possibilitem maior viabilidade para a modernização das atuais práticas de localização dos reservatórios constituintes dos Sistemas Urbanos de Distribuição de Água por meio de SIG.

Por meio das ferramentas de SIG e da análise multicritério, é possível definir regiões para a determinação do melhor caminho (menor custo) entre uma origem e um destino (que pode ter vários pontos). Isso, consequentemente, permite também a construção de modelos de otimização capazes de determinar os locais mais adequados para locação do traçado de adutoras, apontando, assim, alternativas de projeto por meio da simulação de rotas. No presente estudo, utilizou-se o software ArcGIS/ESRI por meio da aplicação ArcMap. O SIG foi usado para calcular o custo de viagem por meio de uma superfície. A análise de custos de viagens envolveu a geração de uma superfície de custo e o cálculo de rotas otimizadas por meio dessa superfície.

\section{Área de estudo}

Para aplicação da metodologia apresentada neste trabalho, utilizou-se como área de estudo apenas um trecho da adutora do Pajeú, situada no estado de Pernambuco. Essa adutora está destinada a transportar 830,7 $\mathrm{L} / \mathrm{s}$ para 20 sedes municipais de Pernambuco, bem como para oito do estado da Paraíba e distritos diversos próximos do traçado da adutora, tendo extensão aproximada de 600 km (CIRILO, 2008). O estudo busca definir quais áreas são mais apropriadas para o traçado de uma adutora para abastecimento das cidades de Serra Talhada (captação da adutora para efeitos de simulação), Calumbi, Santa Cruz da Baixa Verde, Triunfo e Flores, todas localizadas no Estado de Pernambuco. A área de estudo com o traçado de projeto da adutora proposto no Projeto do Sistema Adutor do Pajeú pode ser observada na Figura 1.

\section{O modelo de otimização}

De acordo com a metodologia utilizada neste trabalho, o modelo de otimização é fundamentado na análise multicritério, que, por sua vez, baseia-se no cruzamento dos planos de informações (variáveis) por meio de softwares específicos que permitem a realização de procedimentos para a execução de diagnósticos e prognósticos. No caso do presente estudo, esse método foi utilizado na seleção de rotas para o traçado de um trecho da Adutora do Pajeú. Os critérios e restrições utilizados para definir as áreas com maior aptidão para a locação do traçado da adutora e sua relação com as recomendações de projeto e as informações disponíveis são descritos a seguir. Esses critérios e restrições permitiram também a obtenção das variáveis do modelo:

- Declividade: foi estabelecido que declividades inferiores a $20 \%$ geradas a partir do MDT são adequadas para locação de linhas adutoras. As altas declividades são inadequadas para caminhamento da adutora, pois indicam subidas e descidas acentuadas (obstáculos topográficos), impróprias para sua execução, manutenção e operação, bem como maior probabilidade de necessidade de uso de elementos de proteção contra efeitos transitórios (subpressão e sobrepressão) e formação de bolhas de ar no interior da tubulação; - Distância dos principais rios e áreas alagadas: as áreas consideradas mais adequadas são aquelas que distam, no mínimo, $100 \mathrm{~m}$ de rios (SEMAR, 2012). Áreas alagadas ou muito próximas às margens de rios são inadequadas para locação da adutora. Vale salientar que esse critério tem por objetivo evitar que a locação de uma adutora ocorra margeando um rio, o que é diferente da adutora cruzar um rio, ancorada em uma ponte ou envelopada com concreto e enterrada;

- Distâncias de estradas: foi estabelecido que áreas com distâncias inferiores a $30 \mathrm{~m}$ (regiões dentro da faixa de domínio da rodovia, que é de $30 \mathrm{~m}$ ) são adequadas para a análise (SEMAR, 2012). A proximidade da adutora de uma rodovia ou estradas vicinais é de grande importância para sua implantação, operação e, principalmente, manutenção;

- Altitude: com o objetivo de diminuir custos de energia elétrica com bombeamento, deve-se sempre procurar terrenos com menores desníveis a serem vencidos. Neste trabalho, esse critério consiste em evitar as áreas com altitudes elevadas, considerando que as altitudes nas áreas de estudo variam de 558 a $1.290 \mathrm{~m}$ (adutora do Pajeú, Pernambuco). 
A metodologia utilizada para a determinação do melhor caminho para locação do traçado da adutora foi resumida no fluxograma da Figura 2.

Os procedimentos que permitiram construir o modelo de otimização multicritério, de acordo com o fluxograma da Figura 2, correspondem aos seguintes passos: desenvolvimento de uma base de dados em SIG, que integra dados vetoriais e dados raster; tratamento de dados; obtenção dos planos de informação (variáveis); padronização e ponderação dos planos de informação; aplicação da ferramenta Sobreposição Ponderada (Weighted Overlay); seleção dos locais com maior aptidão para a locação do traçado de adutoras; e determinação do melhor caminho para a locação do traçado de adutoras.

Neste trabalho, foi utilizado o MDT SRTM/TOPODATA com resolução de 30 m (INPE, 2014) e uma base de dados de alta definição do Programa Pernambuco Tridimensional (Programa PE3D) (SRHE, 2014), obtida por meio da tecnologia Light Detection and Ranging (LiDAR). O Programa PE3D, desenvolvido pelo governo do Estado de Pernambuco entre março de 2014 e dezembro de 2017, teve como objetivo maior gerar uma base de apoio às ações de gestão territorial. Esse programa levantou, para todo o território pernambucano, pontos cotados e imagens aéreas de modo a produzir ortofotos na escala 1:5.000 e MDTs e modelos digitais de elevação (MDEs) obtidos por meio de perfilamento laser com erro altimétrico melhor que $25 \mathrm{~cm}$ (CIRILO et al., 2015), por meio da tecnologia LiDAR. Para as principais cidades do estado de Pernambuco, foi realizado mapeamento mais preciso, equivalente à escala 1:1.000. O resultado é uma base de dados com cerca de 80 bilhões de pontos cotados, que está sendo gradualmente disponibilizada na internet, na medida em que os dados são validados.

No caso dos rios e das estradas, foram capturadas as informações disponíveis na base cartográfica do Instituto Brasileiro de Geografia e Estatística (IBGE, 2014) e os dados do Projeto Executivo do Sistema Adutor do Rio Pajeú (BRASIL, 2007). Os conjuntos de dados de entrada MDT, altitudes e áreas de influência (buffer de rios e buffer de rodovias) geraram como resultados os planos de informação: declividade, altitude, distância de rios e distância de rodovias, respectivamente. Após a geração dos buffers, fez-se necessário aplicar a função de distância em linha reta (euclidean distance) do Spatial Analyst (ferramenta do ArcGIS/ ESRI) para o preenchimento de áreas externas, com valores representativos de distância em relação a cada um dos buffers (rios e rodovias).

O uso dos buffers (áreas/faixas de influência) deve-se ao fato de que para alinhamento da adutora é conveniente, para efeito de facilidade na construção e na manutenção de adutoras, a instalação das tubulações dentro de uma faixa de domínio de $30 \mathrm{~m}$ para rodovias federais e $15 \mathrm{~m}$ para rodovias estaduais (SEMAR, 2012). Esse procedimento foi adotado gerando-se um buffer (faixa) de $30 \mathrm{~m}$ das rodovias. Ainda segundo o entrevistado, deve-se procurar manter uma distância mínima de $100 \mathrm{~m}$ de todos os cursos d'água, de forma a evitar que as tubulações venham a ficar submersas e tenham seu funcionamento comprometido (SEMAR, 2012). Nesse sentido, foi gerado também um buffer (faixa) de $100 \mathrm{~m}$ de todos os cursos d'água. Para a geração

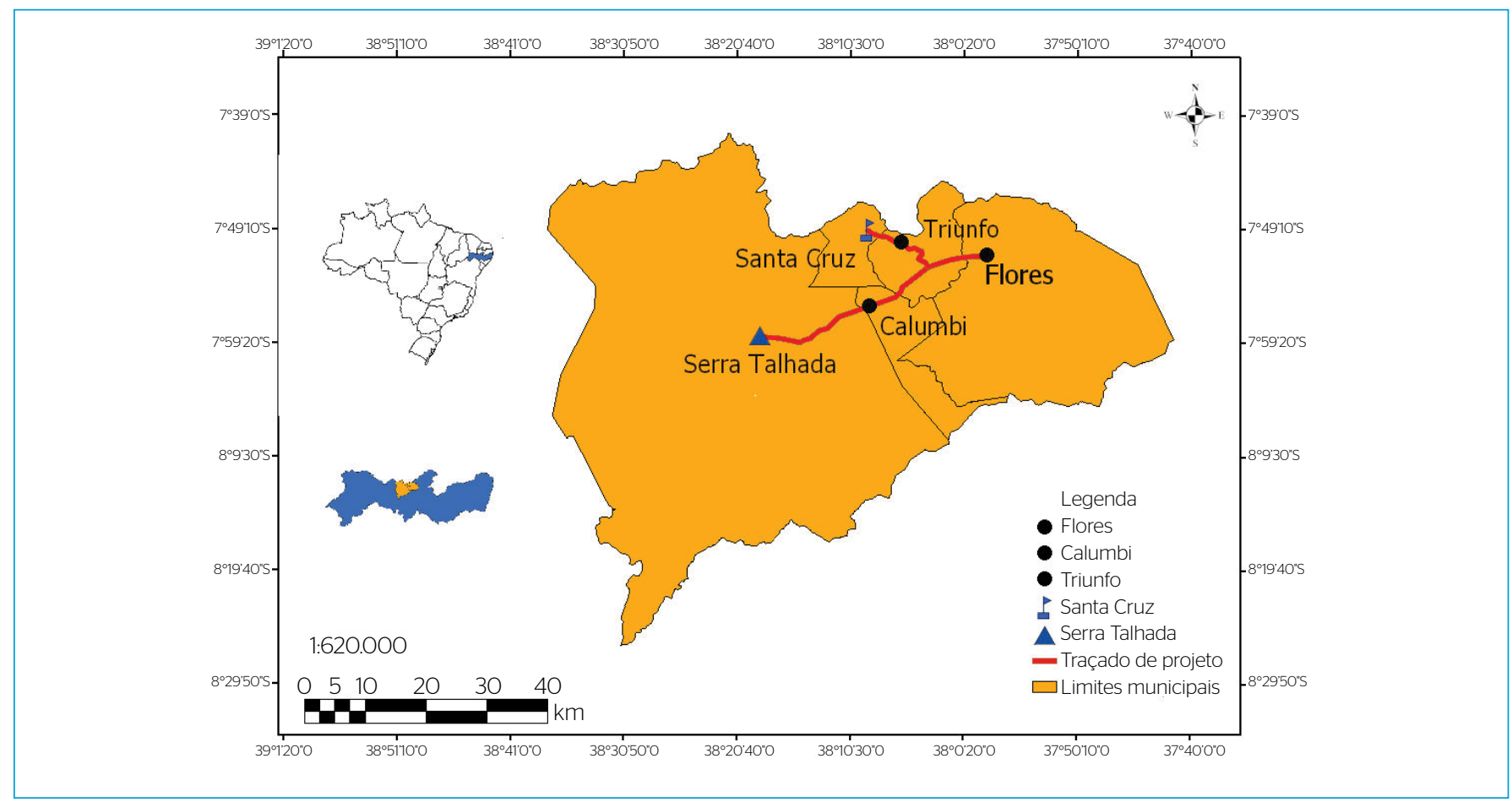

Figura 1 - Área de estudo com o traçado de projeto para a Adutora do Pajeú. 
dos buffers, foram utilizados os arquivos Hidrografia.shp e Rodovias. shp (IBGE, 2014).

Com o objetivo de diminuir custos de energia elétrica com bombeamento, foi gerada uma imagem matricial Altitude_Perda_Carga (variável altitude), obtida da imagem matricial Altitudes, por meio de álgebra de mapas no ArcGIS. Para isso, foi utilizada a Equação 1, na qual o ponto origem representa o ponto de captação da água na cidade de Serra Talhada, e o ponto destino, o ponto final do alinhamento principal da adutora, o qual está localizado na cidade de Santa Cruz, ambas em Pernambuco.

Altitude_Perda_Carga $=($ altitudes $-\Delta \mathrm{Z})+\Delta \mathrm{h}$

Em que:

altitudes = plano de informação altitudes;

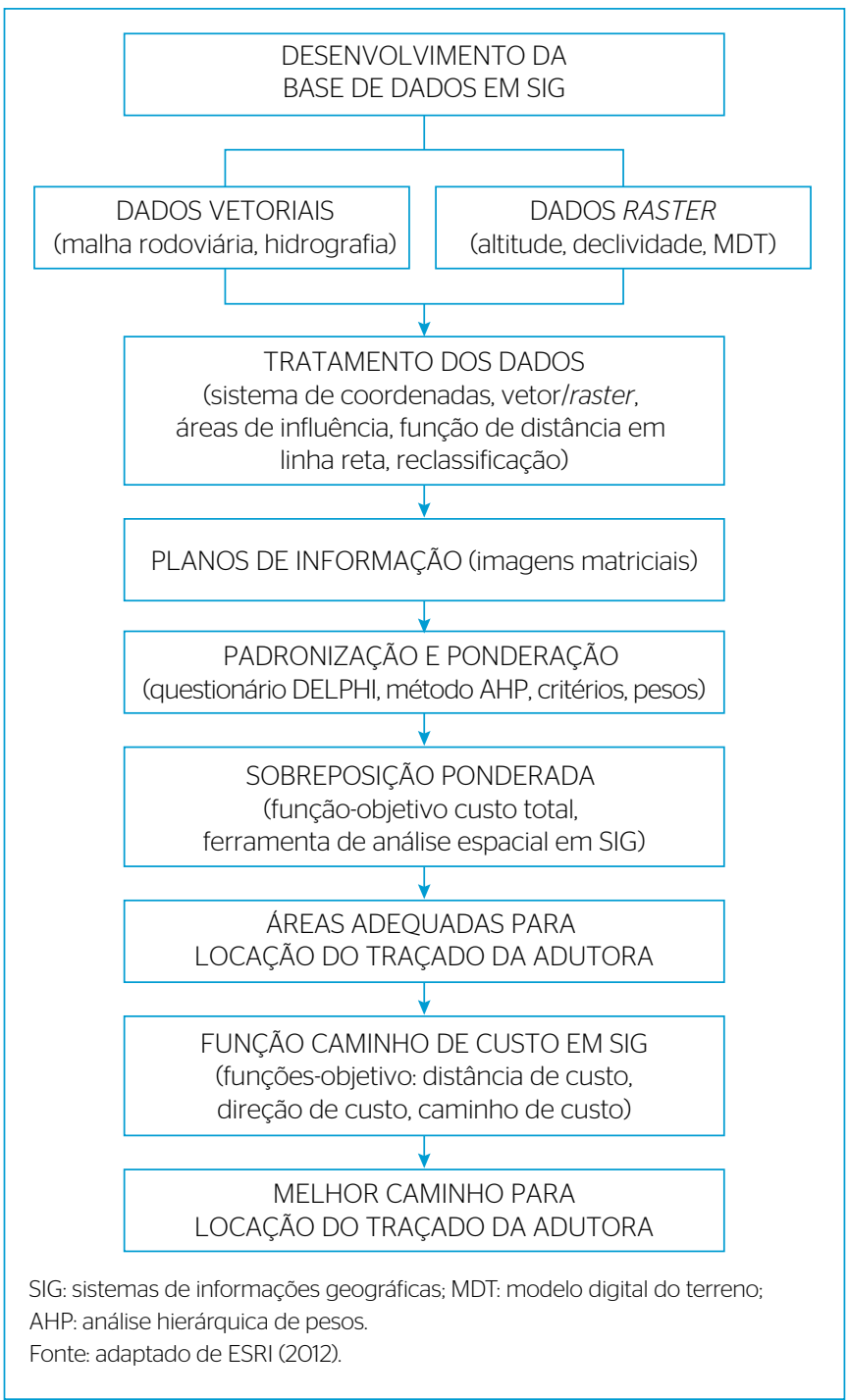

Figura 2 - Fluxograma da metodologia para a determinação do melhor caminho para locação do traçado da adutora.
$\Delta \mathrm{Z}=$ diferença de altitudes (ponto destino - ponto origem);

$\Delta \mathrm{Z}=498-412=86 \mathrm{~m}$;

$\Delta \mathrm{h}=$ perda de carga contínua conforme Equação 2 (em metros).

$\mathrm{J}=\Delta \mathrm{h} / \mathrm{L} \rightarrow \Delta \mathrm{h}=\mathrm{J} \times \mathrm{L}$

Em que:

$\mathrm{J}=$ perda de carga unitária (gradiente ou inclinação da linha de carga em $\mathrm{m} / \mathrm{m})$;

$\mathrm{L}=$ comprimento do conduto, em metros $(\mathrm{L}=58.168 \mathrm{~m})$.

Pela fórmula de Hazen-Williams representada pela Equação 3 (CIRILO, 2011):

$J=\frac{10,64}{C^{1,85}} \frac{Q^{1,85}}{D^{4,87}}=0,0041$

Assim, a Equação 4 apresenta o resultado para o caso em estudo:

$\Delta \mathrm{h}=\mathrm{J} \times \mathrm{L}=0,0041 \times 58168=238,50 \mathrm{~m}$

Em que:

$\mathrm{C}=$ coeficiente de perda de carga $(\mathrm{C}=130$, ferro fundido $)$;

$\mathrm{Q}=$ vazão, $\mathrm{em} \mathrm{m}^{3} \cdot \mathrm{s}^{-1}\left(\mathrm{Q}=130 \mathrm{l} / \mathrm{s}=0,13 \mathrm{~m}^{3} \cdot \mathrm{s}^{-1}\right)$;

$\mathrm{D}=$ diâmetro, em metros $(\mathrm{D}=600 \mathrm{~mm}=0,60 \mathrm{~m})$.

Considerando, então, a metodologia utilizada, os planos de informações obtidos foram reclassificados e padronizados de forma a atenderem aos requisitos das ferramentas do ArcGIS/ESRI. A padronização ou normalização consiste na ponderação das classes presentes em cada plano de informação, e foi realizada por meio da utilização de funções lineares do tipo $y=m x+n$. A atribuição de uma percentagem de influência para cada plano de informação (variável) é necessária e representa a importância (ou peso) que cada um deve ter no mapa final de aptidão. No presente estudo, os pesos para os planos de informação são: altitude, declividade, distância de rios e distância de rodovias.

Entre os diversos métodos utilizados para atribuição de pesos às variáveis estudadas, é possível citar: o método Delphi (ORNELAS, 2011), o método de análise hierárquica de pesos (AHP) (SANTOS; LOUZADA; SILVA, 2010) e os métodos baseados em análises estatísticas. Para determinação dos pesos das variáveis estudadas neste trabalho, foram aplicados os métodos Delphi e AHP. O primeiro busca um consenso, o mais confiável possível, a partir das opiniões de um grupo de especialistas, por meio de uma série de questionários, entremeados por informações sistematizadas que retroalimentam os especialistas. O segundo é um método que auxilia a tomada de decisões complexas. Ele foi desenvolvido por Saaty (1977) e constitui uma técnica de auxílio multicritério à decisão, utilizada na definição de prioridades e 
na escolha da melhor alternativa, podendo ser considerados aspectos quantitativos e qualitativos. O AHP utiliza uma matriz de comparação (matriz de decisão) par a par, que, por sua vez, baseia-se na escala fundamental de Saaty (1977), representada pela Tabela 1, na qual se pode definir linearmente a hierarquia de importância entre os critérios predefinidos. Os valores utilizados na comparação par a par dos planos de informação foram obtidos pela aplicação de um questionário Delphi, para o qual foram entrevistados dez especialistas com reconhecido conhecimento acerca de sistemas adutores.

Os planos de informações, que representam superfícies de custo, foram então combinados para produzir um mapa (superfície de custo total), mostrando os locais com maior aptidão para a locação do traçado da adutora. Para isso, foi utilizada a ferramenta Sobreposição Ponderada para a aplicação da função-objetivo (Equação 5) custo total, descrita a seguir.

Custo_Total $=\mathrm{P}_{1}{ }^{\star}$ Altitude $+\mathrm{P}_{2}{ }^{\star}$ Rodovias $+\mathrm{P}_{3}{ }^{\star}$ Declividade $+\mathrm{P}_{4}{ }^{\star}$ Rios

Em que:

Custo_Total = mapa final de aptidão;

$\mathrm{P}_{1}, \mathrm{P}_{2}, \mathrm{P}_{3}$ e $\mathrm{P}_{4}=$ coeficientes (peso das variáveis);

Altitude, Rodovias, Declividade e Rios = variáveis de decisão.

A função caminho de custo (cost path) do Spatial Analyst foi utilizada para determinar o melhor caminho para o traçado da adutora. Essa função se baseia no Algoritmo de Dijkstra. Segundo Barroso (2014), ele é utilizado para a determinação de um caminho mínimo entre dois nós, n1 e n2, de um grafo, cujos arcos têm valores (pesos) positivos. Esse algoritmo estabelece um equilíbrio por meio do cálculo de um trajeto que é muito próximo do caminho ótimo, computacionalmente possível de ser calculado, partindo a rede em nós e os trajetos entre esses nós sendo representados pelos arcos (SILVA, 2009). Esse algoritmo consiste basicamente em fazer uma visita por todos os

Tabela 1 - Escala de comparação.

\begin{tabular}{c|c} 
Valores & Importância mútua \\
\hline $1 / 9$ & Extremamente menos importante \\
\hline $1 / 7$ & Muito fortemente menos importante \\
\hline $1 / 5$ & Fortemente menos importante \\
\hline $1 / 3$ & Moderadamente menos importante \\
\hline 1 & Igualmente importante \\
\hline 3 & Moderadamente mais importante \\
\hline 5 & Fortemente mais importante \\
\hline 7 & Muito fortemente mais importante \\
\hline 9 & Extremamente mais importante \\
\hline
\end{tabular}

Fonte: Saaty (1977). nós do grafo, iniciando no nó fixo dado e encontrando sucessivamente o nó mais próximo, o segundo mais próximo, o terceiro mais próximo, e assim por diante, um por vez, até que todos os nós do grafo tenham sido visitados (ESRI, 2012).

Essa função determina o caminho de menor custo a partir de um ponto de destino para uma fonte a qual exige que um destino seja especificado e usa dois rasters (imagens matriciais), derivados do uso da ferramenta de distância de custo (cost distance): as imagens matriciais de distância e direção de custo. Essas matrizes são obtidas a partir das funções (distância de custo e direção de custo) que determinam a menor distância ponderada (custo de viagem acumulada) de cada pixel para o pixel mais próximo a partir do pixel de origem, em unidades de custo, e não em unidades geográficas.

A função de caminho de custo (cost path) utiliza as imagens matriciais de distância e direção de custo para encontrar uma rota otimizada (melhor caminho) entre uma origem e um destino. Neste trabalho, o objetivo foi usar essa ferramenta para determinar o melhor caminho entre um ponto de origem (captação do Sistema Adutor do Pajeú, situado na cidade de Serra Talhada) e os destinos correspondentes às cidades de Calumbi, Flores, Triunfo e Santa Cruz da Baixa Verde.

\section{RESULTADOS E DISCUSSÃO}

\section{Determinação dos locais de maior aptidão para locação do traçado da adutora}

A análise do Questionário Delphi dirigido aos especialistas e a aplicação do método AHP resultaram nos valores apresentados nas Tabelas 2 e 3. A Tabela 2 baseia-se na escala fundamental de Saaty (Tabela 1), e foi construída de forma que cada elemento da matriz indica o quanto o fator da coluna da esquerda é mais importante em relação a cada fator correspondente na linha superior. Um fator confrontado com ele mesmo tem valor 1 (um), pois tem a mesma importância. Como todos os fatores se entrecruzam uma vez, a matriz passa a ser apenas um espelho, ou inverso do procedimento inicial. Dessa forma, a Tabela 2 foi obtida pelas diversas informações fornecidas pelos especialistas e selecionadas, por fim, por meio de um procedimento estatístico denominado moda.

A Tabela 3 determina os pesos para cada variável utilizando os valores da Tabela 2, que são determinados dividindo cada elemento pelo

Tabela 2 - Matriz de comparação par a par.

\begin{tabular}{l|c|c|c|c} 
Critérios & Declividade & Estradas & Rios & Altitude \\
Declividade & 1 & $1 / 3=0,33$ & 3 & $1 / 3=0,33$ \\
\hline Estradas & 3 & 1 & 3 & $1 / 5=0,20$ \\
\hline Rios & $1 / 3=0,33$ & $1 / 3=0,33$ & 1 & $1 / 7=0,14$ \\
\hline Altitude_Perda_Carga & 3 & 5 & 7 & 1 \\
\hline
\end{tabular}


somatório dos elementos da coluna a que ele pertence, e realizando uma média entre as colunas, obtendo, assim, os pesos.

Em função dos pesos apresentados na Tabela 3, foi possível estabelecer a ponderação dos planos de informações (variáveis), conforme os critérios mencionados. A Tabela 4 apresenta os planos de informações com seus respectivos pesos, classes e padronização. Uma função linear foi utilizada para cada variável de forma que se obtivesse a padronização. Para a variável declividade, por exemplo, a função encontrada foi $y=0.3 x-2$, em que a grandeza $y$ corresponde aos custos e a grandeza $x$, às declividades. Dessa forma, foi possível atribuir um custo (peso para componente de classe). Considerando, então, os pesos, a Equação 5 pode ser escrita da seguinte maneira:

Tabela 3 - Determinação dos pesos para cada variável.

\begin{tabular}{l|c|c|c|c|c} 
Critérios & Declividade & Estradas & Rios & Altitude & Pesos \\
Declividade & $1 / 7,33=0,14$ & $\begin{array}{c}0,33 / 6,66 \\
=0,05\end{array}$ & $\begin{array}{c}3 / 14= \\
0,21\end{array}$ & $\begin{array}{c}0,33 / 1,67 \\
=0,20\end{array}$ & $\begin{array}{c}0,599 / 4 \\
=0,15\end{array}$ \\
\hline Estradas & $3 / 7,33=0,41$ & $\begin{array}{c}1 / 6,66= \\
0,15\end{array}$ & $\begin{array}{c}3 / 14= \\
0,21\end{array}$ & $\begin{array}{c}0,2 / 1,67 \\
=0,12\end{array}$ & $\begin{array}{c}0,892 / 4 \\
=0,22\end{array}$ \\
\hline Rios & $0,33 / 7,33=$ & $\begin{array}{c}0,33 / 6,66 \\
=0,05\end{array}$ & $\begin{array}{c}1 / 14= \\
0,07\end{array}$ & $\begin{array}{c}0,14 / 1,67 \\
=0,08\end{array}$ & $\begin{array}{c}0,251 / 4 \\
=0,06\end{array}$ \\
\hline Altitude & 0,05 & $\begin{array}{c}5 / 6,66= \\
0,75\end{array}$ & $\begin{array}{c}7 / 14= \\
0,50\end{array}$ & $\begin{array}{c}1 / 1,676= \\
0,60\end{array}$ & $\begin{array}{c}2,256 / 4 \\
=0,57\end{array}$ \\
\hline
\end{tabular}

Tabela 4 - Valores obtidos pela ponderação e pela padronização dos planos de informação (adutora do Pajeú).

\begin{tabular}{|c|c|c|c|}
\hline Variáveis & Pesos (\%) & $\begin{array}{l}\text { Componentes das } \\
\text { classes (metros) }\end{array}$ & Custos \\
\hline \multirow{6}{*}{ Altitude (metros) } & \multirow{6}{*}{57} & $562-688$ & 2 \\
\hline & & 688-814 & 4 \\
\hline & & $814-940$ & 6 \\
\hline & & 940-1.066 & 7 \\
\hline & & 1.066-1.192 & 9 \\
\hline & & $1.192-1.318$ & 10 \\
\hline \multirow{4}{*}{ Declividade (\%) } & \multirow{4}{*}{15} & О\%-10\% & 1 \\
\hline & & $10 \%-20 \%$ & 4 \\
\hline & & $20 \%-30 \%$ & 7 \\
\hline & & $>30 \%$ & 10 \\
\hline \multirow{4}{*}{$\begin{array}{l}\text { Distância_Estradas } \\
\text { (metros) }\end{array}$} & \multirow{4}{*}{22} & $0-30$ & 1 \\
\hline & & $30-60$ & 4 \\
\hline & & $30-60$ & 7 \\
\hline & & $>90$ & 10 \\
\hline \multirow{4}{*}{$\begin{array}{l}\text { Distância_Rios } \\
\text { (metros) }\end{array}$} & \multirow{4}{*}{6} & $0-100$ & 10 \\
\hline & & $100-200$ & 7 \\
\hline & & $200-300$ & 4 \\
\hline & & $>300$ & 1 \\
\hline
\end{tabular}

Custo_Total $=0,57 \mathrm{x}$ Altitude $+0,22 \mathrm{x}$ Rodovias $+0,15 \mathrm{x}$ Declividade $+0,06 \times$ Rios

A Figura 3 mostra a localização da adutora em Pernambuco e os resultados para os locais ou as áreas consideradas de maior aptidão para a locação do traçado da Adutora do Pajeú e o traçado da adutora (traçado de projeto). As variáveis Distância_Estradas, Distância_Rios, Declividade e Altitude, obtidas em função dos critérios estabelecidos e que representam superfícies de custo, foram então combinadas por meio do modelo multicritério para produzir um mapa (superfície de custo total), mostrando os locais com maior aptidão para a locação do traçado da adutora.

Para efeito de diminuição de recursos computacionais para o processamento dos dados, foi utilizada apenas parte (Limites_Estudo) da área de estudo que envolve os municípios a serem atendidos pela Adutora do Pajeú em Pernambuco.

Os resultados apresentados na Figura 3 mostram que as áreas com custos variando de 2 a 4 são as mais indicadas para o traçado da adutora, considerando uma combinação e ponderação dos critérios estabelecidos. As áreas com custos de 5 a 7 apresentam custo médio, enquanto as áreas com custos de 8 a 10 representam os maiores custos. Percebe-se, com a metodologia aplicada, que a comparação das regiões sugeridas na Figura 3 com o traçado de projeto do sistema adutor do Pajeú indica que o traçado projetado para a adutora segue uma rota que se apresenta dentro das áreas consideradas de maior aptidão para a locação do traçado. Com o desenvolvimento do modelo, pode-se observar que a camada de custo (local de maior aptidão para locação do traçado) gerada pode ser usada para identificar potenciais áreas problemáticas para a locação do traçado que possam não ser evidentes em uma primeira avaliação. Segundo Dragan e Jarre (2015), uma área particularmente pode não ter sido considerada um alto custo e baixa área de adequação quando se considera um único fator. No entanto, com a combinação de todos os fatores (camada de custo), pode-se observar a possibilidade de um custo muito mais elevado. Nesses casos, o fato de se ter acesso a essa camada pode ser de grande ajuda no processo de tomada de decisão.

\section{Determinação do melhor caminho para locação do traçado da adutora}

O processo de seleção de rota (melhor caminho), baseado em SIG, foi usado para fornecer uma base racional para selecionar diferentes e potenciais alternativas para a locação do traçado de adutoras. De acordo com o modelo proposto, os resultados são decorrentes da aplicação da função caminho de custo, nesse caso montada sobre o conjunto de ferramentas do Spatial Analyst (ArcGIS). Definida a região de maior viabilidade, como mostrado na etapa anterior, a escolha da melhor rota é feita sobre o conjunto de pontos gerados nessa região. A Figura 4 indica o melhor caminho (menor custo) entre os pontos de origem (Serra Talhada) e os destinos (Calumbi, Flores, Triunfo e 
Santa Cruz) para o traçado da linha adutora do Sistema Adutor do Pajeú. A Figura 4 também indica o traçado da adutora projetado originalmente, os rios e as estradas na região da adutora.

A Figura 4 apresenta a comparação da rota simulada (RO_LiDAR) com o traçado proposto no projeto básico do sistema adutor do Pajeú, a qual indica que há similaridade nesses alinhamentos. No entanto, observa-se que a derivação para a cidade de Triunfo apresentou um traçado diferente: a estação de bombeamento (EB), representada nessa figura, está localizada entre as cidades de Calumbi e Flores e se encontra em um ponto de derivação da adutora, ligando o alinhamento às

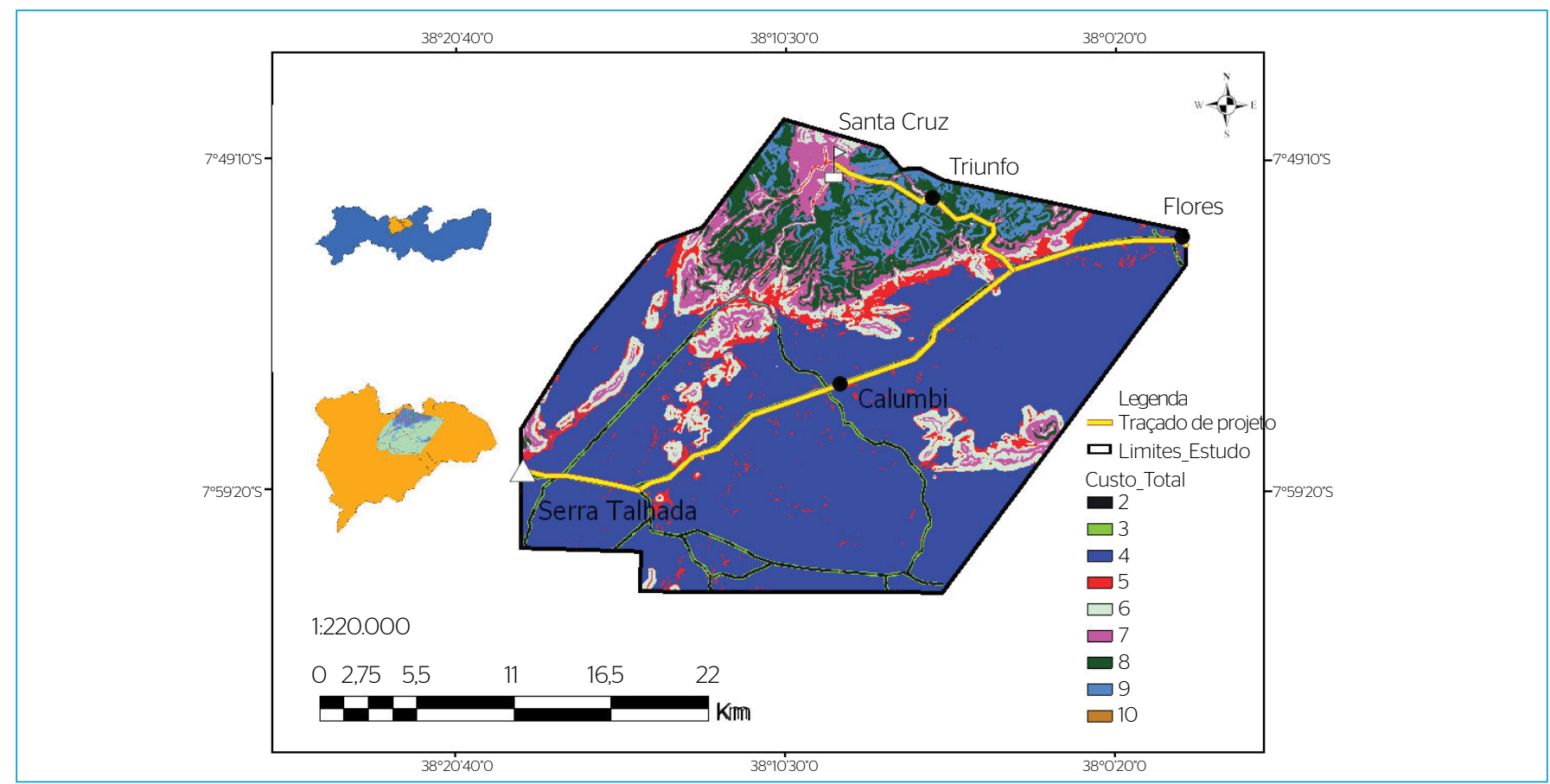

Figura 3 - Resultado para os locais de maior aptidão para o traçado da adutora do Pajeú e o traçado de projeto do sistema adutor do Pajeú.

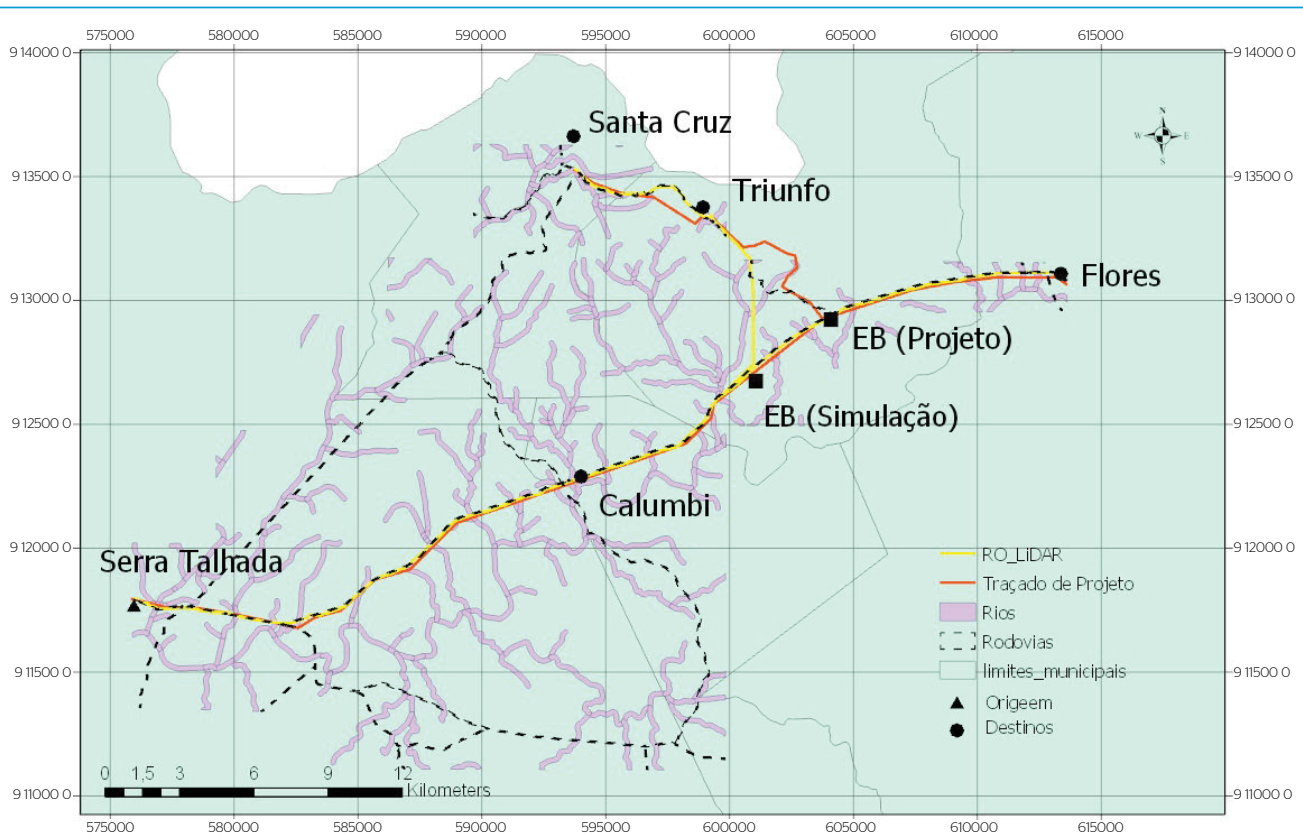

RO_LiDAR: rota simulada Light Detection and Ranging; EB: estação de bombeamento.

Figura 4 - Rota otimizada e traçado do projeto básico do Sistema Adutor do Pajeú (base de dados Light Detection and Ranging). 
cidades de Triunfo e Santa Cruz da Baixa Verde. A sugestão que se apresenta na simulação da rota é que essa derivação seja posicionada em outro ponto do alinhamento. Isso se deve porque, segundo os resultados para as áreas de aptidão para locação da rota, o ponto (derivação na simulação) está em uma região que apresenta menores altitudes e declividades e, consequentemente, menores custos, considerando a diminuição de gastos de energia com bombeamento, de acordo com o modelo aqui proposto.

O comprimento da rota simulada teve um total de 55.160,20 m, o que significa tendência à diminuição de custos com obras e materiais para os tubos, já que a simulação apresenta um percurso menor que a rota original do sistema adutor do Pajeú (56.086,50 $\mathrm{m}$ de comprimento). Um aspecto muito importante a se considerar na análise é a base de dados utilizada. Neste estudo, duas bases de dados espaciais foram usadas: a SRTM/TOPODATA, cujos resultados foram apresentados, e a LiDAR.

A Figura 5 mostra as duas simulações, Rota_Otimizada_SRTM (RO_SRTM) e Rota_Otimizada_LiDAR (RO_LiDAR), por meio das duas bases consideradas (SRTM/TOPODATA e LiDAR, respectivamente). $\mathrm{O}$ trecho em destaque apresenta, em outra escala, as diferenças nas rotas das duas simulações (RO_SRTM e RO_LiDAR).

O traçado simulado com a base de dados espaciais SRTM/ TOPODATA, com resolução espacial de $30 \mathrm{~m}$, teve como resultado o comprimento 55.160,20 m, enquanto com a base de dados LiDAR, com resolução espacial de $1 \mathrm{~m}$, esse traçado apresentou comprimento de 58.303,6 m. A tecnologia LiDAR permitiu a geração de um MDT de alta resolução, que, por sua vez, possibilitou maior precisão nos cálculos. Esse aspecto é essencial no cálculo de rotas, pois apresenta soluções mais precisas e, consequentemente, mais adequadas aos estudos e aos projetos de sistemas adutores. A Tabela 5 resume essas informações.

De forma geral, os dois modelos convergiram para soluções bastante próximas. Deve-se considerar que a geração de um MDT de alta resolução permitiu o cálculo de planos de informação com valores bem mais precisos para altitudes e declividades e, como consequência, maior fidelidade à realidade de campo. Contra a utilização dessa base de dados, pesa o esforço computacional: o processamento teve a duração de várias horas para a obtenção de uma solução, sendo até mesmo necessário aplicar filtros para reduzir a densidade de dados disponível para a área de estudo.

A escolha do traçado significa que, de acordo com a metodologia e os critérios utilizados:

- esses traçados simulados evitam as altas declividades que são inadequadas para o caminhamento da adutora, pois indicariam subidas e descidas acentuadas (obstáculos topográficos), impróprias para

Tabela 5 - Bases de dados e comprimento dos traçados (adutora do Pajeú).

\begin{tabular}{l|c|c} 
Traçado (rota) & Base de dados & comprimento (metros) \\
\hline de projeto & - & $56.086,50$ \\
\hline simulação & LiDAR & $58.303,60$ \\
\hline simulação & SRTM/TOPODATA & $55.160,20$ \\
\hline
\end{tabular}

LiDAR: Light Detection and Ranging; SRTM: Shuttle Radar Topography Mission.

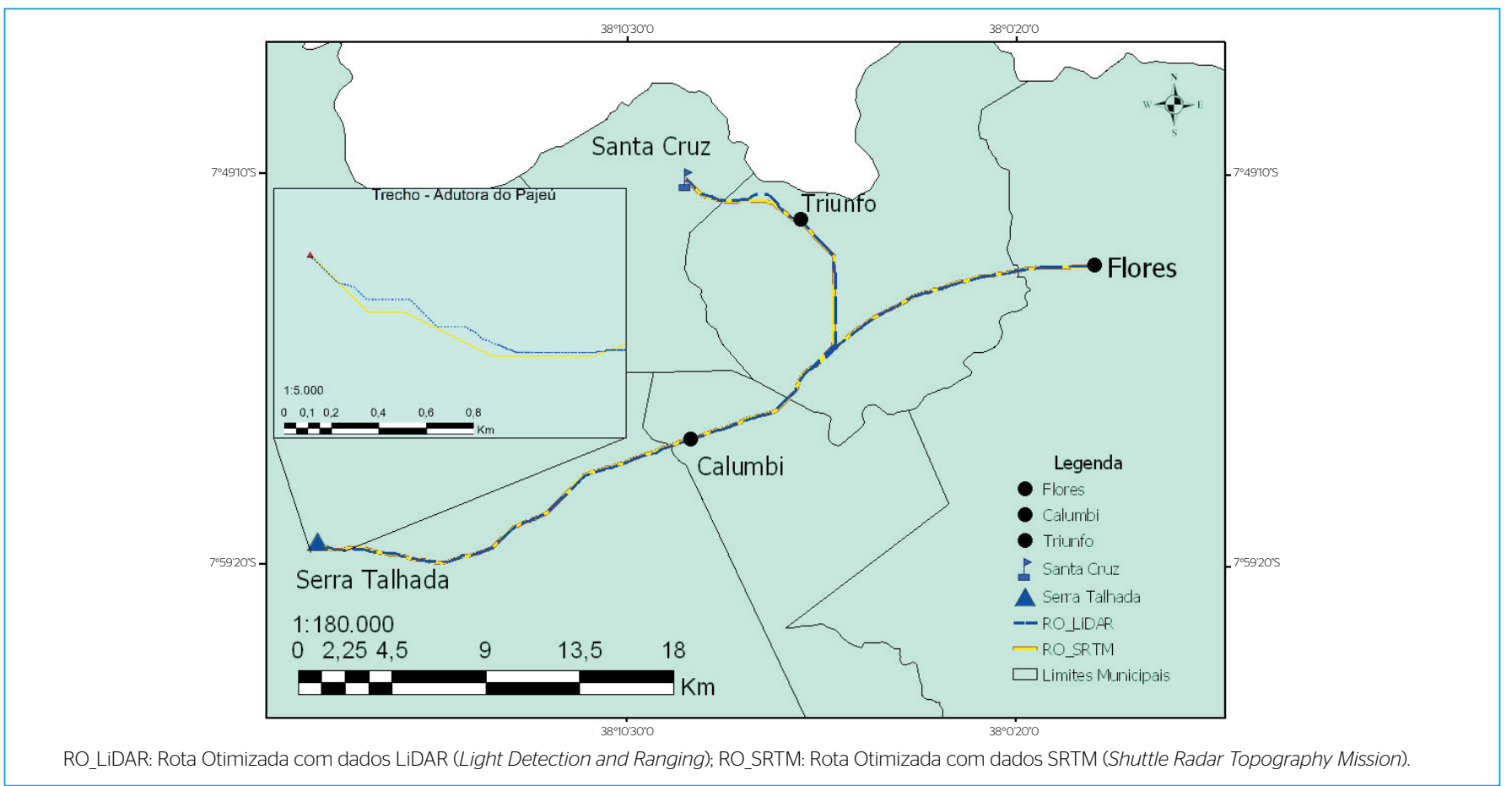

Figura 5 - Rotas otimizadas para o traçado da adutora do Pajeú. 
sua execução, manutenção e operação. Além disso, diminuem as necessidades de uso de elementos de proteção contra efeitos transitórios (subpressão e sobrepressão) e as possibilidades de formação de bolhas de ar no interior da tubulação;

- a análise da rota (traçado otimizado) escolhida também revela que a rota evita o cruzamento desnecessário de rios e áreas alagadas. As áreas consideradas mais adequadas, de acordo com o modelo proposto neste trabalho, são aquelas que distam mais de $100 \mathrm{~m}$ dos rios e das áreas alagadas (uso de buffers). Nesse sentido, as regiões mais próximas aos rios e às áreas alagadas (buffer de 0 a $100 \mathrm{~m}$ ) apresentaram os maiores custos;

- ele segue próximo às rodovias - em uma faixa de domínio de $30 \mathrm{~m}-$ para a maioria do percurso, tal como previsto durante a concepção do modelo. Esse aspecto é de grande importância na implantação, na operação e, principalmente, na manutenção da adutora. As regiões próximas às rodovias (buffer de $0 \mathrm{a} 30 \mathrm{~m}$ ) correspondem às que apresentaram os menores custos segundo o modelo, portanto as mais adequadas;

- o traçado simulado se apresenta em terrenos com menores altitudes, o que diminui custos de energia elétrica com bombeamento. Esse traçado, como mostra a Figura 3, apresenta as maiores diferenças com relação ao traçado original, nos trechos que apresentam diferenças nas altitudes.

\section{CONCLUSÕES}

No que concerne à seleção dos locais com potencial para locação do traçado da adutora, a metodologia apresenta-se como alternativa à padronização e à ponderação dos planos de informações (variáveis espaciais) utilizados. Esse procedimento proporciona o tratamento estatístico da opinião de vários especialistas com relação aos critérios estabelecidos, auxilia na minimização de avaliações tendenciosas e permite a análise de critérios que se utilizam de múltiplas grandezas. Não obstante, a metodologia pode ser utilizada no desenvolvimento de projetos de adutoras em outras regiões, desde que dados e informações estejam disponíveis. O método AHP apresenta-se como uma alternativa viável para a ponderação de múltiplos critérios. O uso do modelo de otimização na determinação do melhor caminho para locação do traçado da adutora, que, em outras palavras, significou a determinação de uma rota para implantação da tubulação, sugere que a utilização de SIG e técnicas de otimização pode auxiliar o processo de tomada de decisão gerencial. Há que se considerar o peso da restrição decorrente do uso da faixa de domínio das estradas, que acaba sendo determinante para a solução. As diferenças seriam mais acentuadas se não existissem as estradas no percurso. Sob o ponto de vista de qualidade da solução, o traçado da solução que utiliza a tecnologia LiDAR é mais fidedigno à realidade de campo. Caso fosse um projeto a ser desenvolvido, a solução seria de grande valia pela riqueza dos detalhes, para definir todos os quantitativos para definição da obra.

Por fim, é importante salientar a necessidade do desenvolvimento de aplicações que incluam outros critérios de tomada de decisão para a locação do traçado de adutoras, como tipo de solo, visto que o custo com a escavação tem elevado peso na composição do custo total da obra. Outra sugestão seria o aperfeiçoamento do critério que melhor representa o consumo de energia com bombeamento. Embora tenha havido bastante coerência entre os traçados obtidos com as condições do relevo e mesmo com as soluções definidas nos projetos de engenharia, é importante desenvolver análise de sensibilidade quanto aos valores dos pesos utilizados, visto que sempre existe o componente de subjetividade.

\section{REFERÊNCIAS}

BALOGUN, A.; MATORI, A.; LAWAL, D.U.; CHANDIO, I. (2012) Optimal Oil Pipeline Route Selection using GIS: Community Participation in Weight Derivation and Disaster Mitigation. In: INTERNATIONAL CONFERENCE ON FUTURE ENVIRONMENT AND ENERGY, 2012, Singapura. Anais... Singapura. Disponível em: <http://www.ipcbee. com/vol28/2O-ICFEE2O12-F10008.pdf>. Acesso em: 12 set. 2014.

BARROSO, M.M.A. (2014) Aplicação de grafos em um problema de rede. Abakós, Belo Horizonte. v. 2, n. 2, p. 48-78.

BRASIL. (2007) Ministério da Integração Nacional/DNOCS. Projeto Executivo do Sistema Adutor do Rio Pajeú. Brasília: Ministério da Integração Nacional.
CIRILO, J.A. (2008) Políticas públicas de recursos hídricos para o semi-árido. Estudos Avançados, v. 22, n. 63, p. 61-82.

CIRILO, J.A.; ALVES, F.H.B.; CAMPOS, P.H.A.L.; SILVA, B.M. (2O15) Pernambuco tridimensional: base de dados espaciais para planejamento urbano e gestão territorial. SILUSBA - SIMPÓSIO DE HIDRÁULICA E RECURSOS HIIDRICOS DOS PAISES DE LÍNGUA PORTUGUESA, 12, 2015, Brasília, Brasil. Anais... Brasília: SILUSBA.

CIRILO, J.A.; BAPTISTA, M.B.; COELHO, M.M.L.P.; MASCARENHAS, F.C.B. (2011) Hidráulica Aplicada. 2. ed. Porto Alegre: ABRH. 628 p.

CORDÃO, M.J.S.; RUFINO, I.A.A.; ARAÚJO, E.L. (2013) Geotecnologias aplicadas ao planejamento de sistemas de abastecimento de água 
urbanos: uma proposta metodológica. Engenharia Ambiental e Sanitária, v. 18, n. 3, p. 263-274. https://doi.org/10.1590/S141341522013000300009

DRAGAN, M.; JARRE, P. (2015) A Spatial MCA Process to Optimize Pipeline Alignment Choiches. HS + E Magazine, Ravenna, v. 12, n. 2 , p. 34-39.

ELMASRI, R.; NAVHATE, S.B. (2004) Fundamentals of Database Systems. 4. ed. Boston: Addison Wesley. 1030 p.

ENVIRONMENTAL SYSTEMS RESEARCH (ESRI). (2O12) Spatial Analyst Tutorial. ESRI.

HARDIN, D.; BRIDGES, G.; RUNDELI, D. (2008) Selecting the best pipeline route based on facts not feelings. Proc., Pipelines Congress, ASCE, Reston, Va, 2008. Disponível em: <http://www.ascelibrary. org/doi/pdf/10.1061/40994(321)12>. Acesso em: O6 dez. 2013.

HUSEYNLI, s. (2015) Determination of the Most Suitable Oil Pipeline Route Using GIS Least Cost Path Analysis. Dissertação (Mestrado) Information Management School, Universidade Nova de Lisboa, Lisboa. Disponível em: <https://run.unl.pt/bitstream/10362/14553/1/ TGEO0138.pdf>. Acesso em: 12 maio 2016.

INSTITUTO BRASILEIRO DE GEOGRAFIA E ESTATÍSTICA (IBGE). (2014) Cartas e mapas. IBGE. Disponível em: <www.ibge.gov.br/>. Acesso em: 16 jul. 2014.

INSTITUTO NACIONAL DE PESQUISAS ESPACIAIS (INPE). (2014) Banco de dados geomorfométricos do Brasil. INPE. Disponível em: <http://www.dsr.inpe.br/topodata/acesso.php>. Acesso em: 23 jul. 2015.

LACERDA, I.S. (2009) Regras de operação para sistemas de abastecimento de água com baixo nível de automação e sujeitos a incertezas. Dissertação (Mestrado em Engenharia Civil e Ambiental) - Universidade Federal de Campina Grande, Campina Grande.

LUETTINGER, J.; CLARK, T. (2005) Geographic Information Systembased Pipeline Route Selection Process. Journal Water Resource Planning Management, v. 131, n. 3, p. 193-200. https://doi.org/10.1061/ (ASCE)0733-9496(2005)131:3(193)
NONIS, C.N.; VARGHESE, K.; SURESH, K.S. (2007) Investigation of an AHP based multi criteria weighting scheme for GIS routing of cross country pipeline projects. In: INTERNATIONAL SYMPOSIUM ON AUTOMATION \& ROBOTICS IN CONSTRUCTION, 24., 2007, Madras. Anais... Madras.

ORNELAS, A.R. (2011) Aplicação de Métodos de Análise Espacial na Gestão dos Resíduos Sólidos Urbanos. Dissertação (Mestrado em Análise e Modelagem de Sistemas Ambientais) - Universidade Federal de Minas Gerais, Belo Horizonte.

ROY, P.; CHANDRAMOHAN, J.; KUMAR, K.V.; RAJ, A.; SHAIK, M.; BOTHALE, V:; DIWAKAR, P.G. (2017) Use of Remote Sensing and Geospatial Technique for Pre-feasibility Analysis of Rural Water Pipeline Grids. Journal of Indian Society of Remote Sensing, v. 45, p. 667-672. http://doi.org/10.1007/s12524-016-0631-0

SAATY, T.L.A. (1977) A scaling method for priorities in hierarchical structures. Journal Mathematical Psychology, v. 15, n. 3, p. 234-281. https://doi.org/10.1016/0022-2496(77)90033-5

SALAH, A.M.; ATWOOD, D. (2011) Pipeline Alignment Optimization: Automated GIS-Based Approach. Journal of Pipeline Systems Engineering and Practice, v. 2, n. 1, p. 2-13. https://doi.org/10.1061/ (ASCE)PS.1949-1204.0000067

SANTOS, A.R.; LOUZADA, F.L.R.O.; SILVA, A.G. (2010) Delimitação de Corredores Ecológicos no ArcGis 9.3. Alegre: Mundo da Geomática. $48 \mathrm{p}$

SECRETARIA DE RECURSOS HÍDRICOS E ENERGÉTICOS DE PERNAMBUCO (SRHE). (2014) Programa Pernambuco Tridimensional. Recife: SRHE. Disponível em: <www.pe3d.pe.gov. br>. Acesso em: 15 out. 2016.

SECRETARIA ESTADUAL DO MEIO AMBIENTE E RECURSOS HÍDRICOS DO PIAUÍ (SEMAR). (2O12) Projeto do Sistema Adutor de Bocaina. Teresina: SEMAR.

SILVA, A.R.E. (2009) Optimização da recolha de resíduos urbanos. Dissertação (Mestrado) - Universidade de Aveiro, Aveiro. Disponível em: <http://ria.ua.pt/bitstream/10773/644/1/2010000210.pdf>. Acesso em: 28 maio 2014. 